\title{
Health Sector and the Transformation Agenda of the Federal Government in Nigeria
}

\author{
Dr. Abiodun J. Oluwabamide \\ Department of Sociology, Ahmadu Bello University \\ Zaria, Kaduna State, Nigeria \\ E-mail:abioduntoluwa@yahoo.com
}

\section{Doi:10.5901/mjss.2014.v5n10p580}

\section{Abstract}

No society can attain any reasonable level of development without giving adequate attention to the health of her population. Over the years, successive governments in Nigeria have given priority to health issues. Recently, the present administration embarked on the transformation of all aspects of the Nigerian society including the health sector, for the purpose of development. Therefore, like other sectors of the country, the transformation of the health sector is ongoing. However, despite the ongoing transformation agenda health care delivery in the country is still generally poor, especially in the rural areas where majority of the population live. This paper therefore, examines the factors inhibiting the success of government's transformation agenda in the health sector. Review shows that the social problems confronting the Nigerian society at large constitute serious impediments to the transformation agenda in all sectors. It is recommended that the government should adopt a zero tolerance approach to social problems such as conflicts, corruption, crime, indiscipline etc, through legislation and intensive public enlightenment using the mass media.

Keywords: Development, social problems, diversion, health facilities, governance.

\section{Introduction}

In every human society government plays a vital role in development. In fact, government is the major facilitator of national development. It supervises and/or directs the processes of development through creating enabling environment, planning, policy formulation and implementation, etc.

It is indeed, no gainsaying that when the government formulates policies and designs programmes that would bring about societal transformation her target is to achieve some development. This is because transformation is change while positive change is development. Since development is change, there cannot be change without an umpire. That umpire is the government.

Recently in Nigeria, the popular slogan associated with the Federal (central) government is the "Transformation Agenda". This is essentially an attempt by the government to carry out the transformation of all sectors of the Nigerian society in order to achieve some level of national development. Obviously, right from the inception of the present administration it has geared its efforts toward transforming such sectors as energy, agriculture, transportation, health, technology, etc. This paper focuses on one of them: the health sector.

Health is a major index for measuring development. It is, in fact, a precondition for development. No society can develop if the health of its population is poor. Therefore, any nation that seeks to develop must pay serious attention to health issues.

Obviously, health is included in the transformation agenda of the Nigerian government. Recently, government functionaries have lauded their own efforts and achievements with respect to the transformation agenda while public opinion sharply differs. Though some transformation has taken place in the health sector but it is not quite obvious to the general public especially the rural dwellers because it is negligible. Hence, health care delivery is still considered by many, as poor. This paper therefore, seeks to identify the factors inhibiting the success of the transformation agenda, especially in the health sector.

\section{The Transformation Agenda}

The transformation agenda originated as the core of President Goodluck Jonathan's manifesto during the 2011 presidential campaigns in Nigeria. In fact, it was what he presented to Nigerians. It was more or less his campaign slogan. Thus, the Nation (2013:1) observes: 
Though there was nothing magical about it (the transformation agenda), the campaign slogan took on a life of its own. The transformation agenda elevated President Jonathan to a would-be messianic figure. Nigerians went into the election and voted him.

The transformation agenda was essentially aimed at changing the way things were done and give the country a new sense of direction. However, as the government of President Jonathan progressed the Transformation Agenda became synonymous with the administration. It became a development framework which aims at transforming various sectors of the entire Nigerian society for the purpose of national development.

During the 2013 Democracy Day celebration, the President presented a mid-term report of his administration as part of the programme. He and later, his ministers, gave the administration a good mark. They claimed that the government's Transformation Agenda has recorded a huge success giving some macro-economic figures. The public was quick to debunk this claim and rejected the figures as incorrect. Even the African Development Bank doubted the GDP figures provided to the public by the government.

Because the figures provided by the government were faulted, the administration began to play low on the figures and turned to encouraging Nigerians to look at the physical structures even if they doubted the figures. For example, Leadership (2013:1) quoted the Minister of Planning as follows:

The Minister of National Planning, Dr. Shamsudeen Usman said the federal government had achieved eight of the 14 key objectives of the transformation agenda. According to the Minister, Nigerians doubted the achievements made by the government judging by macro-economic figures like the GDP growth, but the physical improvement in transportation, aviation and agriculture are not doubtful.

Though two years was not enough for the government to have completely transformed critical sectors of the society, the government created an opportunity for the people to sharply criticize its achievements by coming forward to sing its own praise based on unrealistic figures. It would have been that the people scored the government a pass mark rather than the government scoring itself. It is even more worrisome that the figures presented by the government are misleading. In his reaction to government claims, Shehu Sani, a civil Rights Crusader was reported (The Nation 2013:1) as follows:

Also, president of Civil Rights of Nigeria (CRN) Mallam Shehu Sani described what is going on as a deformation rather than a transformation agenda. He accused the government of presenting misleading statistics saying those who presented them are cut off from the reality on ground in the country.

Nevertheless, some minor achievements have been recorded in areas such as availability of fuel in petrol stations, revival of the railway transportation, repair of few roads, etc. But they are quite insignificant considering the multifarious problems facing the country. From the above discussion, it is obvious that the transformation agenda has not created visible positive impact on Nigerians not only because poverty is still a major challenge to Nigerians but also there are no reasonable physical changes that the people can point at as gains of the transformation Agenda.

\section{Nigeria's Health Care Delivery Strategy}

Since this paper focuses on the health sector, there is the need to take a look at how the sector operates in Nigeria. In Nigeria, health care delivery cannot be discussed without a good understanding of the national health care delivery strategy. The provision of health services is the responsibility of federal, state and local governments as well as religious organizations and individuals (National Population Commission, 2000). This means Nigeria operates a three-tier health care system.

The first tier which is the tertiary health care is in the domain of both the federal and state governments. This level of health care provides highly specialized referral services to both the first and second tiers (primary and secondary levels) of health care delivery system. The second tier is in the domain of the state governments. It is the secondary health care. It provides specialized services to patients referred from the primary health care level. The third tier is the primary health care. This is in the domain of the local governments but with the support of the state Ministry of health. It essentially provides health care for people at the grassroots.

Over the years, the national government had formulated several policies and programmes, all of which were aimed at improving health care delivery services in the country. The Fourth National Development Plan (1981 - 1985) established a government commitment to provide adequate and effective primary health care that was promotive, 
protective, preventive, restorative and rehabilitative to the entire population by the year 2000. Consequently, the Nigerian government adopted a national health policy in1988 to provide a formal framework for the management of the country's health system (Obionu, 2007). The policy was approved by the ruling Armed Forces Ruling Council in1987 and launched in 1988. Its goal was to provide the population with access not only to primary health care but also secondary and tertiary care, as needed through a functional referral system. It was revised in 1997. The revised national policy includes ancillary policies of the main health problems such as HIVIAIDS, malaria, tuberculosis, reproductive health, health management information, etc.

From the discussion so far, it is obvious that the Primary Health Care became a major component of the National health policy. In fact, to-date the national health policy regards primary health care as the framework to achieving improved health for the population. With this focus, it may be said that the national health policy takes cognizance of the health needs of both urban and rural peoples.

\section{Challenges of the Health Sector Before the Transformation Agenda}

In this section, attempt shall be made to examine the performance of the health sector and its challenges prior to the emergence of the transformation agenda of the present administration in Nigeria.

Over the years, the performance of the health sector had been erratic in nature but generally low. However, the primary health care programme was very successful during the tenure of Professor Olikoye Ransome Kuti as the Minister of Health. In the later part of 1980s, coverage of the Expanded Programme on Immunization (EPI) reached about $80 \%$ nationwide, with consequent improvement in maternal and child health (Kyari, 2003). However, there was a drastic decline in subsequent years with some states having very low coverage and even the most effective ones showing a far lower level of effectiveness than previously.

The above notwithstanding, later, the situation changed as most states in the country began to record high percentage coverage. Be that as it may, the country's health care system was still unimpressive because of poor performance. This was because the life expectancy and mortality rates in the country were moving in the negative direction. Thus, Jegede (2002:214) observes:

Rising life expectancy and declining infant mortality rate have long been recognized as key indicators of progress in providing health care. The fact that this trend has continued to move in the opposite direction in Nigeria in spite of all efforts by the World Health Organization (WHO) and donor agencies is indeed a source of worry, especially to the countless people who are giving for better health at every level of the healthcare system

It is obvious therefore, that in Nigeria, the health sector was experiencing failure despite its wide range of activities. According to Jegede (2002), despite repeated policy pronouncements and government promises, very little progress was recorded in the area of child survival. Report has shown that nearly five million babies were born in Nigeria yearly and almost 200,000 of them die before their first birthday, from immunizable diseases (UNICEF, 1996).

Furthermore, in Nigeria, controllable diseases such as tuberculosis, malaria, measles etc claimed millions of lives each year. Of the top 20 major causes of morbidity from rectifiable diseases in 1993, the following infectious diseases ranked high in this order: malaria (1), dysentery (2), pneumonia (3), measles (4), whooping cough (5), chickenpox (9), typhoid and paratyphoid (11) and tuberculosis (12) (Federal Ministry of Health, 1993); Ohadike, 2003). According to the Federal Ministry of health (1993), these together constituted 93.7 percent of all causes. The situation did not change.

The poor health care delivery in Nigeria was further compounded by certain challenges facing the health sector. Firstly, inadequate health personnel. Nigeria lost quite a number of health personnel to brain drain. That is, a number of health care professionals left the shores of Nigeria in search of greener pasture. Apart from that, in Nigeria, medical education was elitist (Jegede, 2002). That is, medical education was mostly accessible to the children of the upper and middle classes. Secondly, healthcare facilities were inadequate. Worst still, their distribution was lopsided. Most of the health facilities were located in the urban centres, rather than in the rural areas where $70 \%$ of the population reside (Kyari, 2003). In Nigeria, most of the curative and hospital-based health facilities were not within the reach of the poor people most of whom encounter health problems in their day-to-day subsistence activities. Thirdly is the high cost of healthcare. In Nigeria, drugs, laboratory tests and medical procedures were generally out of reach of the majority of the population, whether rural or urban (Kyari, 2003). Though the National health Insurance Scheme was designed to help individuals to fund costs of their health needs. This was not achieved. Even if it was, many people especially the rural poor were excluded. Fourthly is lack of access to safe drinking water. In Nigeria, increasing environmental degradation and population have rendered water unsafe. Consequently, water became a commercial commodity. Because of very 
high demand the price of water rose daily making it difficult for the poor to afford safe drinking water.

\section{Has the Situation of Health Care Delivery Changed?}

The government's transformation agenda is ongoing. Hence, attempts are being made to transform various sectors of the country including health. However, despite these attempts health care delivery has recorded no tangible evidence of transformation. This is not to say that there aren't any evidence of transformation in health care delivery at all but they are insignificant.

There has been little improvement such as the provision of few more health facilities, though they are mostly illequipped, creating more access to people who wish to train in health professions, attempt to tackle some health challenges such as malaria and HIVIAIDS. Nevertheless, evidence of such improvements are scanty and lopsided. This is because they are gains which only the urban elites enjoy. For example, the few new hospitals constructed are situated where only the elites can easily utilize them. What of the urban poor and the predominantly poor rural dwellers? While to the priviledged few elites health care delivery may have improved but to the poor majority Nigeria's health care delivery is still as it was before transformation began. It is therefore, crystal clear that despite the transformation agenda of the government there is no serious and/or tangible improvement in Nigeria's health care delivery. Recently, a newspaper report quoted the Director of Public Health in Kaduna State as saying that the primary health care system is in poor condition nationwide. Daily Trust, June 18, 2013:31 reports:

Dr. Zakari (Director of Public Health in Kaduna State Ministry of Health) in an interview told Daily Trust that the poor condition of primary health care system is a national issue and that it is not only restricted to Kaduna State.

Health care facilities are still grossly inadequate for the entire population especially the rural majority. The available ones are too costly for the poor majority. Presently, many Nigerians can still not afford the cost of health care. Furthermore, health problems such as malaria, HIVIAIDS, TB etc still pose serious threats to the people. The most unfortunate thing is that most public hospitals are dilapidated and overcrowded.

Also worrisome is the increasing rate of Nigerians traveling overseas especially India, for treatment. During the $5 \mathrm{pm}$ news of Radio Nigeria Kaduna (on the $1^{\text {st }}$ September, 2013) the chairman of the Nigerian Medical Association was reported as saying that Nigeria looses 185 Billion Naira (N185 Billion) annually to overseas medical tour to India. He disclosed this during the meeting of the executive of the Association in Sokoto. The agelong overseas medical tour by Nigerians has been increasing rather than decreasing. This is retrogression. It is also an indication that Nigeria's health care delivery is still inadequate and poor. Consequently, many more Nigerians are seeking for result-oriented or better health care in India. It is pertinent to note that traveling to India is very costly. Only the high and middle socio-economic status persons can afford traveling overseas for treatment. While the former can easily afford the cost the latter often depend on contributions from friends and relatives or loans. There is still the unfortunate poor majority who cannot afford the cost of medical trip overseas. These low socio-economic status persons often resort to fate when their relatives are terribly sick. Some died of sickness which would have been cured if Nigeria's health care delivery is effective.

\section{Impediments to the Success of the Transformation Agenda}

The present administration meant well with the slogan "Transformation Agenda". Nevertheless, not much has been achieved during the administration's two years in office. A number of factors constitute serious impediments to the efforts of the government so far. These factors which cut across the various segments of the Nigerian society have limited the success of the transformation agenda. The factors are discussed in this section. It is pertinent to note that the lack of reasonable improvement in the health sector, which is the focus of this paper, is as a result of the general impediments to the success of the transformation agenda as a whole regardless of the sector.

Firstly, the enormous security challenges facing the country. Recently, security challenges have taken much of government's attention such that the present administration could not settle down to execute its transformation agenda policies and other development programmes. Worst still, resources that the administration would have used in transforming the various sectors including health are committed to security.

Just before the present administration came to power in 2011 some strange security problems began to manifest in the Nigerian society. They are here referred to as strange because they were initially very new in the history of Nigeria. The security challenges include kidnapping, large scale armed robbery and terrorism. They involved the use of sophisticated ammunitions and explosives and/or bombs. Also they take human lives in large numbers. In the case of 
terrorism many lives are often lost in one single incident. Terrorism involves the use of bombs and explosives.

Right from the emergence of the present administration, the most worrisome security challenge to her was the frequent cases of bombings by the Boko Haram insurgents in the Northern part of the country. In fact, from the beginning of the tenure of the administration to-date bombings (blasts) have been a common occurrence. The prominent ones include the bombing of the Police Force Headquarters in Abuja, the bombing of the United Nations Office in Abuja, the Christmas day bombing of a church in Madala near Abuja and several other cases of church bombings etc. Thousands of people have died as a result of these and other cases of bombings within the two years of the present administration.

From the above, it is obvious that the government has no other choice than to direct all her energy into combating the security problems facing the country most especially terrorism. This implies that development programmes have to suffer. This explains why some of the transformation agenda projects are not adequately funded, supervised and implemented to achieve the desired result. For example, funds that would have been used in procuring more health facilities throughout the country were directed to security problems. The country's Minister of Justice was reported as saying that terrorist attacks in Nigeria affect cost of governance. Thus, The Nation, (August 27, 2013:7) reports

The Attorney General of the Federation (AGF) and Minister of Justice, Mr. Mohammed Bello Adoke (SAN), yesterday said terrorists' attacks have been affecting the cost of governance.

The Minister of Information was reported to have made a similar statement in another occasion. The Nation, (September 4, 2013:6) reports:

He (Mr. Labaran Maku, the Minister of Information) said the huge amount spent to restore peace following Boko Haram insurgency in the North would have been used to finance education and other sectors.

Obviously, the above comments buttress the point that security challenges have seriously diverted the Federal government's attention from the transformation agenda and development. These are high ranking government functionaries confirming that other sectors have been grossly underfunded due to the diversion of funds to the security sector to combat the problem of terrorism.

Secondly, the menace of corruption. As earlier mentioned the transformation agenda itself is laudable but its execution or implementation is the problem. Throughout Nigeria's history the country's underdevelopment status has never been attributed to poor policies or programmes but rather to problems associated with policy implementation and project monitoring. One major hindrance to proper implementation of development policies is corruption.

Corruption has been described as the bane of Nigeria (Dike, 2008). According to Adisa et al (2010), the problem of corruption in Nigeria is so alarming that the corporate entity of the country is often called into question. Also in the words of Arukwe (2010:40), "systematic corruption in Nigeria has become somewhat established with far-reaching consequences for economic development". Corruption has been entrenched in virtually all aspects of the country's life. In Nigeria, all public institutions (including health) are currently not credible in the eyes of many Nigerian households and companies (Business Anti-corruption Portal, 2009 cited in Arukwe, 2009).

Corruption cuts across all spheres of the Nigerian society. That is, it is not restricted to public office holders only. In fact, corruption occurs in homes, markets, places of worship, schools, private businesses etc. Corruption is therefore deep rooted in Nigeria. That funds available for the transformation of the various sectors, are inadequate is not the only problem, but there is still the problem of misuse of the funds. Oftentimes, funds meant for development purposes are used for personal aggrandizement.

Obviously, Nigeria's successive health care policies including the transformation agenda in the health sector have no doubt, been good but the implementation has always been the problem. Health care policy implementations often failed. However, this is not peculiar to the health sector alone. Large scale corruption occurs mostly at the policy implementation level in every sector of the country. Let us now take a closer look at the problem of corruption in the health sector.

Every year, huge sums of money were allocated by the government for the provision of health facilities throughout the country. But it is sad to note that these facilities are still lacking nationwide especially in the rural areas. Primary Health Care centres which are expected to be situated within the reach of the rural people are not found in many rural communities. Meanwhile, funds are said to have been allocated at various times, for the provision of minimal health facility in all rural communities, but they are never widely spent on them as required. Even in those rural communities where primary health care centres are provided, other basic health care needs such as drugs are totally absent. Meanwhile, on the government's documents, drugs are said to have been paid for and supplied to various health facilities. Definitely, such money must have been diverted into private pockets. Or where the drugs are bought at all, they are diverted into private clinics. In few areas where the drugs are faithfully supplied, those health care personnel whose duty was to dispense them sometimes divert them into their personal pharmacy shops and clinics.

A national daily sometimes reported that $50 \%$ of Nigerian women received antenatal care from skill providers (Daily 
Trust, December 1, 2009). Quoting the National Population Commission (NPC) in its National Demographic Health Survey (NDHS), the newspaper said that "84\% of urban women as well as $46 \%$ of women in the rural areas received adequate antenatal care from health providers". This figure shows a healthcare delivery failure in the rural areas where $70 \%$ of Nigerians live. This lopsidedness is a form of corruption. The report also implies that antenatal care providers and facilities are grossly inadequate in the rural areas. Meanwhile, on government's records these care providers and facilities are said to have been sent to all the rural areas. It is obvious that funds meant for this purpose have been diverted into private pockets.

The Expanded Programme on Immunization (EPI) is also affected by corruption. In most communities especially in the remote areas, the programme has not actually created any serious impact. Firstly, immunization officers did not reach larger part of the remote rural areas. They often collected their honorariums but only provided the services in few areas and at the end they claimed to have reached all the expected areas. Secondly, immunization drugs were often said to be exhausted quickly whereas in most cases, they were either under-supplied or diverted to other use by key officers in the immunization control office.

A report in one of the dailies said that HIVIAIDS epidemic in Nigeria has continued to claim new casualties despite all efforts to nip it (Weekly Trust, April 17, 2010, Daily Trust, August 16, 2012). This report is very worrisome considering the large sums of money that had been spent on the HIVIAIDS menace over the years. Definitely, corruption is one of the factors responsible for this state of affairs. In a report titled "7BN Malaria HIV Funds Frittered" Daily Trust (June 28, 2011:1,5) reports:

About N7 billion donor funds sent to Nigeria for the fight against malaria, HIV and TB were frittered away, according to an audit report by the International Agency that provided the funds

In another report titled "ICPC to probe NACA, Six Others Over \$30M Grants", the same newspaper reports on page 4 as follows:

The ICPC yesterday said it will soon probe the National Action on HIVIAIDS in Nigeria (NACA) and six other nongovernmental organizations in respect of the management of over $\$ 30$ million grants.

All the above reports point to the fact that there was indeed, an accusation of corruption against the handlers of the funds meant for HIVIAIDS eradication. This might have been one of the factors responsible for the slow success recorded in the fight against HIVIAIDS in Nigeria.

Thirdly, bad leadership. The transformation agenda has been affected by bad leadership. It is indeed, not an understatement that there cannot be development where there is no good leadership. Therefore, to some extent, the poor performance of the health sector despite the ongoing transformation agenda is due to bad leadership not only in the health sector but the entire Nigerian society.

Generally, the level of seriousness and commitment of leaders determine the success of any programme. The low level of success recorded so far in the ongoing transformation agenda would have been the opposite if leaders at various levels and/or sectors of the Nigerian society have shown commitment. Funds might not be adequate but if leaders ensure that they personally monitor and supervise the various projects they are meant to direct or control, a great success would be achieved.

In Nigeria, leaders are mostly armchair supervisors. When government releases funds for specific the projects leaders in charge often monitor such projects from their comfortable offices rather than visiting sites where the projects are being executed. As a result of this bad leadership style some projects are not executed and where they are executed at all, substandard materials are used because the leader never border to cross-check at the site.

Most of the leaders in Nigeria do not live by example. If leaders at the highest level of authority are corrupt, definitely leaders at lower levels would do the same. Similarly, if leaders at the highest levels are honest, the lower level leaders would follow their good example. As mentioned earlier, corruption is rife in the Nigerian society and this is partly because there are corrupt leaders who are bad examples for lower level leaders.

Fourthly, the unnecessary diversion of government's attention to the 2015 elections. For more than one year there has been serious preparations by leaders in government, for 2015 elections, which is still two years away. State governors hardly sleep in their states; they attend series of long meetings with the President in Abuja to discuss strategies for 2015 elections. The President is involved in political meetings to strategize for 2015 elections. Worst still, the ruling party (the Peoples Democratic Party) has been witnessing series of crises on the issue of 2015 elections. These crises create serious tension for leaders in government and therefore they require full concentration of the President and his team. They lack time to plan for and supervise the transformation agenda projects in virtually all the sectors of the country. Usually, all the ministers are involved in various political meeting targeting the 2015 elections.

From the above, it is obvious that the transformation agenda and overall national development have suffered some setbacks due to lack of attention by government functionaries. They spent greater part of their time on political meetings 
to search for elective positions ahead of 2015.

\section{Conclusion}

From independence to-date Nigeria's status as an underdeveloped country has not changed though it has witnessed some developmental strides. The country is yet to be classified as developed despite her enormous human, material and natural resources. Obviously Nigeria is naturally endowed with abundant resources it requires to attain a reasonable level of development but unfortunately the country is still underdeveloped.

Over the years, successive governments have made attempts to transform the country from its underdeveloped status to a developed one, but all to no avail. They have formulated various policies and designed programmes meant to enhance development but they all suffered serious setbacks because of either non-implementation or poor implementation. The most recent one is the transformation agenda of the present administration which has not achieved any reasonable success. For example, in the health sector not much has changed since the emergence of the transformation agenda. The country's health care delivery is still poor.

The factors responsible for the poor performance of the transformation agenda range from government's focus on security challenges, corruption, bad leadership to unnecessary shift of attention from governance to planning ahead for the 2015 elections. For the transformation agenda to succeed, a number of things needed to be done. Some recommendations are hereby made.

Firstly, the government should adopt a zero tolerance approach to social problems such as indiscipline, crime, corruption, conflicts, bad leadership, conflicts etc through legislation and intensive public enlightenment. Secondly, the government should not because of the seriousness of security challenges facing the country abandon its developmental programmes. While they are making an attempt to solve the security challenges, they should also concentrate on their development agenda. Thirdly, the government should take the issue of corruption seriously as it has done for security. The government should create a true atmosphere of freedom and independence for the various anti-corruption agencies to operate. The government should stop interfering with the affairs of the agencies forthwith. Fourthly, government functionaries should stop the unnecessary preparations for the 2015 elections and concentrate on governance in order to achieve the objectives of the transformation agenda. As long as they focus their attention on the 2015 elections, they will hardly have time to execute their development programmes.

\section{References}

Adisa, W.B., Jawando, J. \& Oyenuga, A. (2010). Corruption, public service and the challenges of development in Nigeria. The proceedings of the $15^{\text {th }}$ Annual conference of the Nigerian Anthropological and Sociological Association. pp. 13-25

Arukwe, N.O. (2010). Corruption research; Its place in knowledge and sustainable development in Nigeria and elsewhere. The proceedings of $15^{\text {th }}$ Annual Conference of the Anthropological and Sociological Association. pp. 40-50

Business Anti-corruption Portal (2009). Nigeria: Country profile [Online] Available: http:llwww.business-anti-=corruption.com/country-profile/sub-saharanafrica/Nigeria/initiative/private-anti-corruption-initiative (June 13, 2010).

Daily Trust, (2009) $58 \%$ of women receive antenatal care. Tuesday December 1, pp.43

Daily Trust, (2011). N7bn malaria HIV funds frittered. Tuesday June 28, pp.1, 4, 5.

Daily Trust, (2012). 1000 HIVIAIDS infections recorded daily in Nigeria. Thursday August 16, pp.6

Daily Trust. (2013). Health bill will improve health care. Tuesday June 18, pp.31

Dike, V.E. (2008). Corruption in Nigeria: A new paradigm for effective control. African Economic Analysis. [Online] Available: www.africaneconomicanalysis.org (January 4, 2009).

Federal Ministry of Health (1993). Nigeria health profile 1992 - 1998. Lagos: Department of Planning Research and Statistics, pp.5-6.

Jegede, S.A. (2002). Problems and prospects of Health care delivery in Nigeria: Issues in political economy and social inequality. In,U.C.I. Isiugo=Abanihe, A.N. Isamah \& J.O. Adesina (Eds). Currents and perspectives in sociology (pp.82-97). Lagos: Malthouse Press Limited.

Kyari, F. (2003). Population growth for health needs: A case study of Plateau state. In, National Population Commission (Ed). Data needs for sustainable development in the $21^{\text {st }}$ century. (pp.123-133). Abuja: National Population Commission.

Leadership (2013). Transformation Agenda: FG Achieved 8 of the 14 Objectives, say Minister. [Online] Available: Leadership.ng/news/290513/transformation=agenda-fg-achieved-8-14-objectives-says-minister. (September 2, 2013).

National Population Commission (2000). National demographic and Health Survey 1999. Abuja: National Population Commission

Obionu, C.N. (2007). Primary health care for developing countries ( $2^{\text {nd }}$ ed.). Enugu: Institute of Development Studies.

Ohadike, P.O. (2003). Population growth and health needs in Nigeria. In: National Population Commission (Ed) Data needs for sustainable development in the 21 $1^{\text {st }}$ century, (pp. 141-152) Abuja: National Population Commission.

The Nation (2013). Is the Transformation Agenda on course? [Online] Available: the nationonlineng.net/news/is-transformation-agenda-on-course-3/ (, August 27, 2013)

The Nation, (2013). Terrorists' attacks affect cost of governance says Adoke. Tuesday, August 27, pp. 7.

The Nation. (2013). Fed. Govt.: Meeting ASUU's demand can shut down Nigeria. Wednesday September 4, pp.6

UNICEF (1996). The state of the world's children. Geneva: UNICEF.

Weekly Trust, (2010). Nigeria losing battle against HIV/AIDS. Saturday, April 17, pp.2 